A $\mathrm{\text {publications }}$ G Rec. Nat. Prod. 14:5 (2020) 378-382

records of natural products

\title{
A New Labdane Diterpene from the Aerial Parts of Chloranthus serratus
}

\author{
Ming Zhao $\oplus^{1}$, Gang Chen $\odot^{2}$, Tingting Lin $\oplus^{2 *}$ and Yu Lu@ ${ }^{*}$ \\ ${ }^{1}$ Xuyi People's Hospital, Xuyi, 211700, P.R. China \\ ${ }^{2}$ Jiangxi Provincial People's Hospital, Nanchang 330006, P.R. China
}

(Received February 20, 2020; Revised March 17, 2020; Accepted March 25, 2020)

\begin{abstract}
A new labdane diterpene (1) and five known compounds (2-6) were isolated from the aerial parts of Chloranthus serratus. The gross structure of compound $\mathbf{1}$ was resolved by NMR and HRESIMS data. The absolute configuration of $\mathbf{1}$ was determined by comparing CD spectrum and specific rotations with those of the co-isolated known analogue 2. The known compounds were identified to be agathic acid (2), altechromone A (3), chlorajapolide F (4), shizukanolide (5), and chloranthalactone E (6) by comparing the NMR data with those in the literature. All compounds were evaluated for their inhibitions against NO production in LPS-activated RAW 264.7 macrophages, compounds 2 and 6 showed moderate inhibitions with $\mathrm{IC}_{50}$ values of $45.2 \pm 1.2$ and $35.3 \pm 0.9 \mu \mathrm{M}$.
\end{abstract}

Keywords: Chloranthus serratus; labdane diterpene; inhibitions; NO production. (C) 2020 ACG Publications. All rights reserved.

\section{Plant Source}

The aerial part of Chloranthus serratus were collected in November 2014 in Guangdong Province, P. R. China. Identity of the species was identified by Prof. Lin Jiang of School of Pharmaceutical Sciences, Sun Yat-sen University, Guangzhou. The voucher specimen (accession number: SYXS201411) was deposited at Jiangxi Provincial People's Hospital.

\section{Previous Studies}

Chloranthus serratus is a perennial herb widely distributed in Southern China, especially in Anhui, Zhejiang, Hunan, Fujian, and Guangdong Provinces [1]. It is used for the treatment of bruises, furuncles, snakebites, and rheumatoid arthritis in Traditional Chinese Medicine (TCM) [1]. Previous investigations of the constituents of this species resulted in the isolation of lindenane sesquiterpenoids [2,3], eudesmane sesquiterpenoids [4], phenylpropanoids [2], and labdane diterpenoids [5], several sesquiterpenoids showed antimicrobial and anti-inflammatory effects.

\footnotetext{
*Corresponding author: E-Mail: lintingting_1988@163.com (T. L), zyf160119@126.com (Y. L)
} 


\section{Present Study}

The air-dried powder of the aerial parts of $C$. serratus $(1.5 \mathrm{~kg})$ was extracted with $75 \% \mathrm{EtOH}(3 \times$ $5 \mathrm{~L})$ at room temperature (rt) to give $105 \mathrm{~g}$ of crude extract. The extract was suspended in $\mathrm{H}_{2} \mathrm{O}(1 \mathrm{~L})$ and further extracted with petroleum ether $(3 \times 0.5 \mathrm{~L})$ and EtOAc $(3 \times 0.5 \mathrm{~L})$, respectively. The EtOAc extract $(80 \mathrm{~g})$ was separated over MCI gel chromatographic column (CC) using $\mathrm{MeOH} / \mathrm{H}_{2} \mathrm{O}(3: 7 \rightarrow$ 10:0) as eluent to give five fractions (I-VI). Fraction IV was subjected to silica gel CC (petroleum ether /acetone, 20:1 $\rightarrow 1: 1$ ) to give five fractions (IVa-IVe). IVa was subjected to Sephadex LH-20 (ethanol) to obtain two fractions (IVb1-IVb2), further purification of IVb1 by silica gel CC (petroleum ether/ EtOAc, 20:1 $\rightarrow$ 5:1) yielded $\mathbf{5}$. IVb was purified by silica gel CC (petroleum ether/acetone, 2:1 $\rightarrow 1: 1$ ) to give 3, 4, and 6. IVe was applied to sephadex LH-20 to obtain three subfractions (IVe1-IVe3), fraction IVe3 was further purified by HPLC (YMC ODS column) using $\mathrm{CH}_{3} \mathrm{CN} / \mathrm{H}_{2} \mathrm{O}$ (55:45) as eluent to obtain 1 and $\mathbf{2}$ (Figure 1).<smiles>C=C1CC[C@@]2(C)[C@H]1CCC(=C)[C@H](O)[C@@H]2CC/C(C)=C/C(=O)O</smiles>

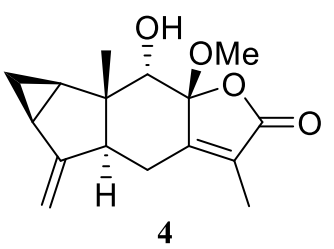

4<smiles>C=C1CCC2[C@](C)(C(=O)O)CCC[C@]2(C)[C@H]1CC/C(C)=C/C(=O)O</smiles><smiles>C=C1C2CC2C2(C)CC3=C(C)C(=O)O[C@H]3CC12</smiles><smiles>C=C1C2C[C@H]2C2(C)[C@@H]1CC1=C(C)C(=O)O[C@@]1(O)[C@@H]2O</smiles><smiles>C=C1CC[C@H]2[C@@H](C(=O)O)C[C@@H](O)C[C@]2(C)C1CC/C(C)=C/C(=O)O</smiles>

1a (relative configuration)

Figure 1. Structures of compounds 1-6 and 1a

Compound 1: colorless oil; $[\alpha]^{25}{ }_{D}+61(c 0.1, \mathrm{MeOH})$; UV $(\mathrm{MeOH}) \lambda_{\max }(\log \varepsilon) 216$ (3.67); HRESIMS $m / z 373.1986[\mathrm{M}+\mathrm{Na}]^{+}$(calcd for $\mathrm{C}_{20} \mathrm{H}_{30} \mathrm{O}_{5} \mathrm{Na}^{+}, 373.1991$ ).

Compound 1 was obtained as a colorless oil. Its molecular formula, $\mathrm{C}_{20} \mathrm{H}_{30} \mathrm{O}_{5}$, was determined on the basis of its high-resolution ESIMS (HRESIMS) spectrum and the ${ }^{13} \mathrm{C}$ NMR data, indicating 6 degrees of unsaturation. The ${ }^{1} \mathrm{H}$ NMR spectrum of $\mathbf{1}$ displayed resonances attributable to three methyl groups $\left[\delta_{\mathrm{H}} 2.09(\mathrm{~s}), 1.34(\mathrm{~s})\right.$, and $\left.0.66(\mathrm{~s})\right]$ including an olefinic methyl $\left(\delta_{\mathrm{H}} 2.09\right)$, two protons for a terminal olefinic methylene $\left[\delta_{\mathrm{H}} 4.52(\mathrm{~s})\right.$ and $\left.4.87(\mathrm{~s})\right]$, a proton bonded to carbons bearing heteroatoms $\left[\delta_{\mathrm{H}} 3.15(\mathrm{dd}, J=12.0,4.2 \mathrm{~Hz}, \mathrm{H}-3)\right]$. The ${ }^{13} \mathrm{C}$ NMR and HSQC spectra exhibited 20 carbon resonances, including three methyls $\left(\delta_{\mathrm{C}} 13.5,18.9,24.7\right)$, six sp ${ }^{3}$ methylenes $\left(\delta_{\mathrm{C}} 39.6,38.7,29.7,27.2,23.0,40.7\right)$ and one $\mathrm{sp}^{2}$ methylene $\left(\delta_{\mathrm{C}} 107.2\right)$, three $\mathrm{sp}^{3}$ methines $\left(\delta_{\mathrm{C}} 79.0,56.4 \times 2\right)$ and one sp $\mathrm{sp}^{2}$ methine $\left(\delta_{\mathrm{C}} 116.9\right)$, two $\mathrm{sp}^{3}$ quaternary carbon $\left(\delta_{\mathrm{C}} 50.3,41.0\right)$ and four $\mathrm{sp}^{2}$ quaternary carbon $\left(\delta_{\mathrm{C}} 149.0,161.7,170.4,180.5\right)$. The low-field magnetic resonances above $100 \mathrm{ppm}$ suggested the presences of two double bonds and two carbonyl carbon, which accounted for four degrees of unsaturations, the remaining two degrees of unsaturation required that compound $\mathbf{1}$ was bicyclic. The aforementioned structural features were very similar to those of a co-isolated known analogue, agathic acid (2). The obvious distinction between $\mathbf{1}$ and 2 was due to the presence of an additonal oxygenated methine $\left(\delta_{\mathrm{H}} 3.15, \delta_{\mathrm{C}} 79.0\right)$ in 1 instead of one methylene in $\mathbf{2}$, indicating that compound $\mathbf{1}$ is a hydroxylated derivative of $\mathbf{2}$, this was supported by the MS data. The hydroxy group was located at C-3 by the HMBC correlations of $\mathrm{H}_{3}-18$ to C-3 and the ${ }^{1} \mathrm{H}-$ 
${ }^{1} \mathrm{H}$ COSY correlations from $\mathrm{H}_{2}-1\left(\delta_{\mathrm{H}} 1.20,1.88\right)$ to $\mathrm{H}-3\left(\delta_{\mathrm{H}} 3.15\right)$. The gross structure of 1 was confirmed by detailed analyses of the 2D NMR data (Figure 2 ).

Table 1. NMR data of $\mathbf{1}, \mathbf{2}$, and $\mathbf{1 a}$ in $\mathrm{CD}_{3} \mathrm{OD}^{a}(\delta$ in ppm)

\begin{tabular}{|c|c|c|c|c|}
\hline \multirow{2}{*}{ No. } & $\mathbf{1}^{a}$ & & $2^{a}$ & $\mathbf{1 a}^{b}$ \\
\hline & $\delta_{\mathrm{H}}($ mult., $J$ in Hz) & $\delta_{\mathrm{C}}$ & $\delta_{\mathrm{C}}$ & $\delta_{\mathrm{C}}$ \\
\hline 1 & $\begin{array}{l}1.20, \mathrm{~m} \\
1.88, \mathrm{~m}\end{array}$ & $38.7, \mathrm{CH}_{2}$ & $40.8, \mathrm{CH}_{2}$ & $46.2, \mathrm{CH}_{2}$ \\
\hline 2 & $\begin{array}{l}1.75, \mathrm{~m} \\
2.12, \mathrm{~m}\end{array}$ & $29.7, \mathrm{CH}$ & $21.1, \mathrm{CH}$ & $64.2, \mathrm{CH}$ \\
\hline $\begin{array}{l}3 \\
4\end{array}$ & $3.15, \mathrm{dd}(12.0,4.2)$ & $\begin{array}{c}79.0, \mathrm{CH}_{2} \\
50.3, \mathrm{C}\end{array}$ & $\begin{array}{c}39.8, \mathrm{CH}_{2} \\
45.1, \mathrm{C}\end{array}$ & $\begin{array}{c}47.0, \mathrm{CH}_{2} \\
44.6, \mathrm{C}\end{array}$ \\
\hline 5 & $1.25, \mathrm{~m}$ & $56.4, \mathrm{CH}$ & $57.4, \mathrm{CH}$ & $55.3, \mathrm{CH}$ \\
\hline 6 & $\begin{array}{l}1.90, \mathrm{~m} \\
2.00, \mathrm{~m}\end{array}$ & $27.2, \mathrm{CH}_{2}$ & $27.5, \mathrm{CH}_{2}$ & 25.7, $\mathrm{CH}_{2}$ \\
\hline 7 & $\begin{array}{l}1.90, \mathrm{~m} \\
2.38, \mathrm{~m}\end{array}$ & $39.6, \mathrm{CH}_{2}$ & $40.4, \mathrm{CH}_{2}$ & $38.2, \mathrm{CH}_{2}$ \\
\hline $\begin{array}{c}8 \\
9 \\
10\end{array}$ & $1.58, \mathrm{~m}$ & $\begin{array}{c}149.0, \mathrm{C} \\
56.6, \mathrm{CH} \\
41.0, \mathrm{C}\end{array}$ & $\begin{array}{c}149.4, \mathrm{C} \\
56.6, \mathrm{CH} \\
41.5, \mathrm{C}\end{array}$ & $\begin{array}{c}147.4, \mathrm{C} \\
55.2, \mathrm{CH} \\
40.9, \mathrm{C}\end{array}$ \\
\hline 11 & $\begin{array}{l}1.70, \mathrm{~m} \\
1.54, \mathrm{~m}\end{array}$ & 23.0, $\mathrm{CH}_{2}$ & $22.8, \mathrm{CH}_{2}$ & 21.6, $\mathrm{CH}_{2}$ \\
\hline 12 & $\begin{array}{l}1.98, \mathrm{~m} \\
2.27, \mathrm{~m}\end{array}$ & $40.7, \mathrm{CH}_{2}$ & $39.3, \mathrm{CH}_{2}$ & $39.3, \mathrm{CH}_{2}$ \\
\hline $\begin{array}{l}13 \\
14 \\
15 \\
16\end{array}$ & $2.09, \mathrm{~d}(1.2)$ & $\begin{array}{c}161.7, \mathrm{C} \\
116.9, \mathrm{CH} \\
170.4, \mathrm{C} \\
18.9, \mathrm{CH}_{3}\end{array}$ & $\begin{array}{c}161.9, \mathrm{C} \\
116.8, \mathrm{CH} \\
170.3, \mathrm{C} \\
18.9, \mathrm{CH}_{3}\end{array}$ & $\begin{array}{c}160.3, \mathrm{C} \\
115.4, \mathrm{CH} \\
168.9, \mathrm{C} \\
17.5, \mathrm{CH}_{3}\end{array}$ \\
\hline 17 & $\begin{array}{l}4.52 \text {, br s } \\
4.87 \text {, br s }\end{array}$ & 107.2, $\mathrm{CH}_{2}$ & 106.9, $\mathrm{CH}_{2}$ & 106.2, $\mathrm{CH}_{2}$ \\
\hline $\begin{array}{l}18 \\
19 \\
20\end{array}$ & $1.34, \mathrm{~s}$ & $\begin{array}{c}24.7, \mathrm{CH}_{3} \\
180.5, \mathrm{C} \\
13.5, \mathrm{CH}_{3}\end{array}$ & $\begin{array}{c}29.5, \mathrm{CH}_{3} \\
181.2, \mathrm{C} \\
13.4, \mathrm{CH}_{3}\end{array}$ & $\begin{array}{c}28.1, \mathrm{CH}_{3} \\
179.2, \mathrm{C} \\
12.8, \mathrm{CH}_{3}\end{array}$ \\
\hline
\end{tabular}

${ }^{a}{ }^{1} \mathrm{H}$ NMR $(400 \mathrm{MHz}),{ }^{13} \mathrm{C}$ NMR (100 MHz). ${ }^{b} \mathrm{H}$ NMR $(600 \mathrm{MHz}),{ }^{13} \mathrm{C}$ NMR $(150 \mathrm{MHz})$.

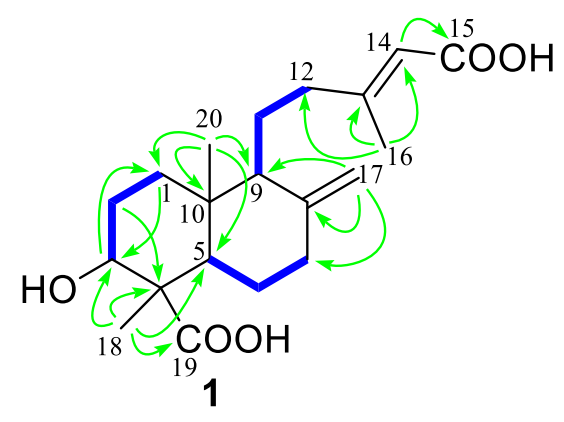

Figure 2. ${ }^{1} \mathrm{H}-{ }^{1} \mathrm{H} \operatorname{COSY}(-)$ and $\mathrm{HMBC}(\rightarrow)$ correlations of $\mathbf{1}$

The relative configuration of $\mathbf{1}$ was determined to be the same as that of $\mathbf{2}$ by comparing their ${ }^{13} \mathrm{C}$ NMR data, NOESY data, and coupling constants, (Figure 3). The NOE correlations from $\mathrm{H}_{3}-20$ to $\mathrm{H}-$ $6 \beta, \mathrm{H}-2 \beta$ and between $\mathrm{H}-5$ with $\mathrm{H}-9, \mathrm{H}-3, \mathrm{H}-1 \alpha$ assigned $\mathrm{H}-3, \mathrm{H}-5$, and $\mathrm{H}-9$ to be $\alpha$-orientated, while $\mathrm{H}_{3}-20$ was in the opposite orietation. Besides, $\mathrm{OH}-3$ was confirmed to be $\beta$-orientated by the coupling constants of $J_{\mathrm{H}-3 / \mathrm{H}-2 \beta}(12.0 \mathrm{~Hz})$ and $J_{\mathrm{H}-3 / \mathrm{H}-2 \alpha}(4.2 \mathrm{~Hz})$. 


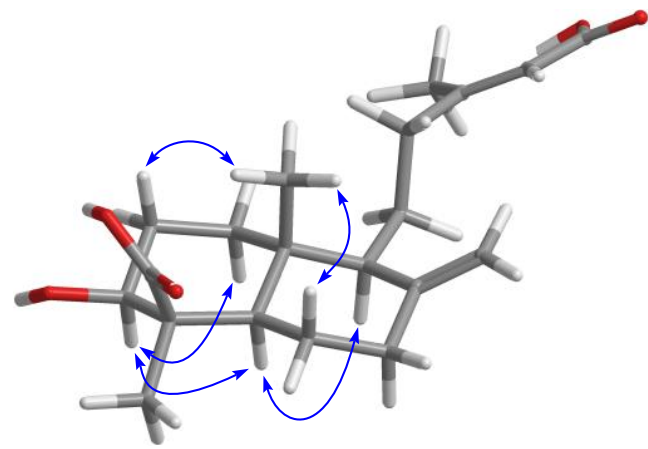

Figure 3. NOE correlations $(\longleftrightarrow)$ ) of $\mathbf{1}$

The absolute configuration of $\mathrm{C}-3, \mathrm{C}-4, \mathrm{C}-5, \mathrm{C}-9$, and $\mathrm{C}-10$ was determined to be $S, R, R, S, R$ based on their similar optical rotations $\left(\mathbf{1}:[\alpha]^{25} \mathrm{D}+61 ; \mathbf{2}:[\alpha]^{25} \mathrm{D}+48\right)$ and $\mathrm{CD}$ spectra of 1 and 2 [6] (Figure 4). Compound 1 was given the trivival name serralabdane $\mathrm{F}$.

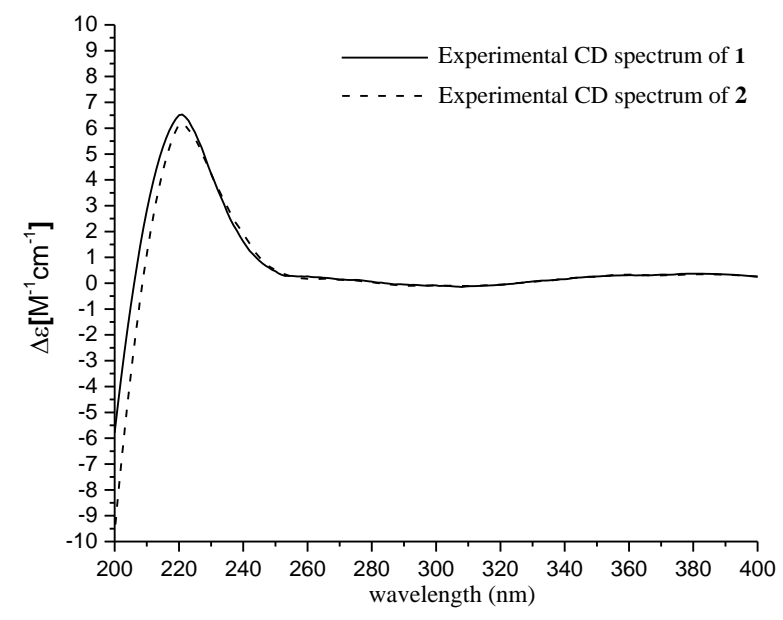

Figure 4. CD spectra (200-400 nm) of compounds $\mathbf{1}$ and $\mathbf{2}$

Compound 1 was an isomer of the known compound 1a with the distinction owing to the location of the hydroxy group [6]. Totally, four labdane diterpenes were isolated from Chloranthus serratus in previous study [5], our study added new members to the labdane diterpenes from this plant. The known compounds were identified to be agathic acid (2) [7], altechromone A (3) [8], chlorajapolide F (4) [9], shizukanolide (5) [10], chloranthalactone E (6) [11] by comparison of their NMR data and specific rotations with those in the literature.

All compounds were tested for inhibitions against NO production in LPS-activated RAW 264.7 macrophages following the same procedures in the literature [3], as results, compounds $\mathbf{2}$ and $\mathbf{6}$ exhibited moderate inhibitory effects with $\mathrm{IC}_{50}$ values of $45.2 \pm 1.2$ and $35.3 \pm 0.9 \mu \mathrm{M}$, while the positive control quercetin possessed an $\mathrm{IC}_{50}$ of $15.2 \pm 1.3 \mu \mathrm{M}$.

\section{Supporting Information}

Supporting Information accompanies this paper on http://www.acgpubs.org/journal/recordsof-natural-products 


\section{ORCID}

Ming Zhao: 0000-0002-0632-9259

Gang Chen: $0000-0002-3945-4371$

Tingting Lin: 0000-0001-6953-720X

Yu Lu: 0000-0001-6953-720X

\section{References}

[1] Y. Q. Chen., D. Z. Cheng, G. F. Wu, P. S. Cheng and P. Z. Zhu (1982). In Chinese Flora (Zhongguo Zhiwu Zhi); Science Press: Beijing, 20, 80-96.

[2] T. Yuan, C.R. Zhang, S.P. Yang, S. Yin, W.B. Wu, L. Dong and J.M. Yue (2008). Sesquiterpenoids and phenylpropanoids from Chloranthus serratus, J. Nat. Prod. 71, 2021-2025.

[3] B. Bai, S.X. Ye, D.P. Yang, L.P. Zhu, G.H. Tang, Y.Y. Chen, G. Q. Li and Z.M. Zhao (2019). Chloraserrtone A, a sesquiterpenoid dimer from Chloranthus serratus, J. Nat. Prod. 82, 407-411.

[4] F. Teng, H.M. Zhong, C.X. Chen and H.Y. Liu (2009). Four new eudesmane sesquiterpenoid lactones from Chloranthus serratus, Helv. Chim. Acta 92, 1298-1303.

[5] M. Zhang, J. Wang, J. Luo, P. Wang, C. Guo and L. Kong (2013). Labdane diterpenes from Chloranthus serratus, Fitoterapia 91, 95-99.

[6] K. Zhou, X.L. Zhao, L.P. Han, M.M. Cao, C. Chen, B.Z. Shi and D.Q. Luo (2015). Paecilomycines A and B, novel diterpenoids, isolated from insect-pathogenic fungi Paecilomyces sp. ACCC 37762, Helv. Chim. Acta 98, 642-649.

[7] Z. Xin, Y. Lu, X. Xing, J. Long, J. Li and X. Xue (2016). Synthesis of (-)-agathic acid and (-)-copalic acid from andrographolide via a regioselective Barton-McCombie reaction, Tetrahedron 72, 555-562.

[8] L. Liu, W. Xu, S. Li, M. Chen, Y. Cheng, W. Yuan, Z. Cheng and Q. Li (2019). Penicindopene A, a new indole diterpene from the deep-sea fungus Penicillium sp. YPCMAC1, Nat. Prod .Res. 33, 2988-2994.

[9] M. Zhang, J.S. Wang, P.R. Wang, M. Oyama, J. Luo, T. Ito, M. Iinuma and L.Y. Kong (2012). Sesquiterpenes from the aerial part of Chloranthus japonicus and their cytotoxicities, Fitoterapia 83, 1604-1609.

[10] J. Kawabata, S. Tahara, J. Mizutani, A. Furusaki, N. Hashiba and T. Matsumoto (1979). Shizukanolides, two sesquiterpenoids from Chloranthus japonicus (Chloranthaceae), Agric. Biol. Chem. 43, 885-887.

[11] M. Uchida, Y. Koike, G. Kusano, Y. Kondo, S. Nozoe, C. Kabuto and T. Takemoto (1980). Studies on the constituents of Chloranthus spp. III. Six sesquiterpenes from Chloranthus japonicus, Chem. Pharm. Bull. 28, 92-102.

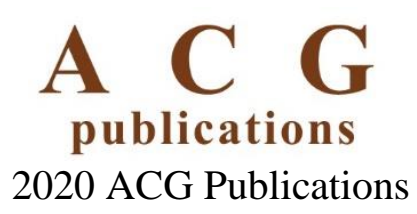

